\title{
Posicionamento Estratégico em Turismo: o caso Sabre Brasil
}

\section{Strategic Positioning in Tourism: Sabre Brazil case study}

\author{
Braulio Oliveira ${ }^{1}$ \\ Marcos Cortez Campomar² \\ Carolina Luis ${ }^{3}$
}

\begin{abstract}
Resumo
A definição de um direcionamento estratégico que vise coordenar as ações empresariais e otimizar os recursos empregados, bem como a maneira como o público-alvo observa e interpreta esse direcionamento em termos relativos aos direcionamentos dos concorrentes da empresa é fundamental para o sucesso de um negócio. Esse artigo apresenta o estado da arte relativa ao posicionamento estratégico e os resultados de uma pesquisa que teve por objetivo principal conhecer o processo de posicionamento estratégico realizado por uma empresa atuante no setor de turismo. Realizado pelo método do estudo de caso, os dados coletados evidenciam a importância do procedimento tal como descrito na literatura, e colocam a cultura organizacional como um fator crítico para o sucesso do processo, além de chamar a atenção para a necessidade do monitoramento contínuo do ambiente empresarial, como forma de contribuir para o seu sucesso e a sua longevidade.
\end{abstract}

Palavras-chave: posicionamento estratégico; competitividade em turismo.

\begin{abstract}
The definition of an estrategic-driven that aims to coordinate enterprises actions and optimize used resources, as well as the way as the target observes and interprets this driven in relative terms to the competitors-drivens of the company is basic for the success of a business. This paper presents the state of the art relating to strategic positioning and the results of a research that had as aim to know the strategic positioning process carried out by a company operating company in the tourism sector. Carried out for the method of the case study research, the collected data show the importance of the procedure such as described in literature, and place organizational culture as a critical factor for the success of the process, besides calling the attention for the necessity of the continuous cheking of the entrerprise enviroment, as form to contribute for its success and its longevity.
\end{abstract}

Keywords: strategic positioning; tourism competitiveness

\footnotetext{
${ }^{1}$ Doutor em Administração pela FEA/USP, professor da FIA. E-mail: braulio@usp.br

${ }^{2}$ Livre-Docente em Administração pela FEA/USP, professor Titular do Departamento de Administração da FEA/USP. E-mail: campomar@usp.br

${ }^{3}$ Graduada em Administração pela FEA/USP. Endereço: R. José Alves da Cunha Lima, 172, Butantã, São Paulo- SP
} 


\section{Introdução}

A necessidade de as empresas serem competitivas, em razão da pressão de diversos fatores, faz com que instrumentos e técnicas de gestão empresarial ganhem visibilidade e sejam utilizados de maneira mais contundente. No entanto, setores econômicos que estão em franco desenvolvimento, como é o caso do turismo, muitas vezes perdem o timing correto acerca dessa prática, justamente em virtude de as preocupações voltarem-se ao atendimento da demanda e à resolução de problemas internos das organizações, desconsiderando, ao menos em parte, a busca pela eficácia dos processos e a definição de uma estratégia competitiva clara e que permita o desenvolvimento e a sustentação de vantagens no longo prazo.

À medida que a competição se acirra, as empresas precisam buscar maneiras de se consolidarem nos mercados em que atuam, sob pena de não desenvolverem uma posição sólida no longo prazo, o que dificulta a atração e a manutenção de clientes, especialmente se empresas concorrentes o fizerem.

Em vista da sua relevância enquanto prática empresarial e da carência de estudos específicos que abordam o assunto em organizações que atuam no setor de turismo, esse artigo discorre sobre o posicionamento estratégico como uma importante ferramenta para o desenvolvimento da competitividade organizacional e apresenta os resultados de um estudo de caso realizado na Sabre Brasil, uma empresa atuante no setor de turismo.

Este artigo está dividido em seis partes, contando com essa introdução. A segunda parte fundamenta a competição entre empresas; a terceira parte expõe a teoria relativa ao posicionamento estratégico, as estratégias e os processos teóricos para a sua realização; a quarta parte discorre sobre a metodologia da pesquisa empírica; a quinta parte apresenta os resultados da pesquisa de campo, compreendendo a caracterização da empresa e a descrição das variáveis operacionais trabalhadas; a sexta e última parte apresenta as conclusões do trabalho.

\section{Direcionamento Competitivo}

No atual contexto geopolítico mundial a competitividade é requisito fundamental para o desenvolvimento das empresas. Uma empresa pouco competitiva tem dificuldade de contribuir para a sociedade em que está inserida, pois a sua sobrevivência pode estar em risco no longo prazo, ao passo que, aquela mais competitiva, busca cada vez mais a hegemonia, o desenvolvimento e a sustentação de vantagens sobre as demais. 
A competição entre as organizações existe basicamente porque um ou mais player atual ou potencial, de um determinado setor econômico, percebe a oportunidade de melhorar sua posição (ou estabelecê-la), ou sente-se pressionado por outro player. Isso ocorre porque os movimentos de uma empresa repercutem nas demais, por haver uma relação de interdependência. Desta forma, é constante a busca por alternativas que permitam às organizações sobrepujar as ações dos seus concorrentes, uma vez que, se não o fizerem, acabarão por receberem impactos das ações deles, o que pode ser prejudicial e criar situações difíceis de serem revertidas.

Nesse contexto, as empresas devem criar, desenvolver e sustentar vantagens em relação aos seus concorrentes, de forma que lhes permita crescer e se desenvolver em ambiente competitivo.

O termo vantagem competitiva, amplamente divulgado por Michael Porter no início dos anos 80, diz respeito justamente ao direcionamento que uma organização deve trilhar, como forma de criar e sustentar vantagens em relação aos seus concorrentes, a fim de contribuir para a sua lucratividade e o seu desenvolvimento. O referido autor apontou, então, três direcionamentos estratégicos que as empresas podem adotar, com vistas a obtê-la: liderança em custo, diferenciação e foco - este combinado com custo ou diferenciação (PORTER, 1986).

A liderança em custo é adotada pela empresa que deseja ser o produtor de mais baixo custo em sua indústria, obtido através de, por exemplo, economia de escala, tecnologia patenteada, acesso preferencial a matérias-primas, entre outras possibilidades. Geralmente comercializa um produto padrão, que não tem capacidade de exceder a expectativa do consumidor, porém é interessante por conta de seu baixo preço. Porter (1986) lembra que desenvolver um produto padrão não significa que as necessidades dos consumidores não devem ser levadas em conta; em outras palavras, é necessário que o produto apresente ao menos um nível de diferenciação que seja capaz de equipará-lo aos principais concorrentes.

A estratégia de diferenciação conduz a empresa a tentar obter vantagem através de ofertas altamente valorizadas pelos consumidores, mesmo que mais custosas. O custo maior não é um impeditivo, porque os consumidores dispõem-se pagar um preço-prêmio por produtos que são percebidos como mais capazes de satisfazerem suas necessidades, o que não significa que se possa descuidar de sua estrutura de custos, pois isto comprometeria os resultados da empresa. Marketing é a principal forma de obtenção de vantagem competitiva através da diferenciação. 
Se a estratégia genérica escolhida pela empresa é o foco, ela deve delimitar um segmento de mercado no qual atuar e não se comprometer a atender outros segmentos ou à indústria como um todo. A partir da escolha do segmento, ela deve combinar a estratégia de foco com liderança em custo ou diferenciação para obter vantagem competitiva.

Muito embora o mesmo autor apresente as três “estratégias genéricas” com o intuito de guiar as ações empresariais a fim de se criar uma posição defensável a longo prazo, o aumento da competitividade, em razão da maior acessibilidade a bens, know-how e capital, fez com que os direcionamentos estratégicos propostos passassem a ser questionados, sobretudo em termos de operacionalização e de sustentabilidade. Ressalte-se que o próprio autor apontou, naquela ocasião, dois riscos inerentes à sua proposta: o primeiro, não conseguir criar ou sustentar a estratégia escolhida; e, o segundo, que os benefícios advindos da estratégia escolhida fosse desgastado com a evolução do setor (PORTER, 1986, p. 58).

Observa-se que em mercados concorridos, o relacionamento entre uma empresa e os seus clientes pode ser interpretado como a base para a melhoria do potencial competitivo dela. Essa assertiva decorre da própria conceituação de marketing, que ressalta que o alcance dos objetivos de uma organização subordina-se à satisfação proporcionada aos clientes, uma vez que o relacionamento pode deturpar-se quando eles sentem-se insatisfeitos com ela. Nesse contexto, a orientação para o mercado é condição essencial às empresas para que possam sobreviver e se desenvolver, pois tem como elemento subjacente a interação com os principais fatores que as influenciam diretamente: os consumidores e a concorrência.

Esse direcionamento organizacional emerge como fundamental em mercados competitivos porque, de acordo com Machado (1999, p. 21), no passado as trocas eram focadas no produto e, atualmente, são focadas no cliente. Assim sendo, para conseguir maior probabilidade de êxito nos mercados em que atua, uma empresa deve conduzir seus esforços em prol deles. Day (1999, p. 14) sustenta que isso ocorre quando ela desenvolve habilidades superiores para entender, atrair e conservar clientes valiosos, e aponta diversos benefícios advindos da orientação para o mercado, como:

- Maior eficácia dos investimentos;

- Satisfação dos colaboradores;

- Possibilidade de se cobrar preços superiores (premium);

- Crescimento do faturamento;

- Criação de barreiras de entrada aos concorrentes potenciais. 
Nesse contexto, o posicionamento torna-se fundamental, pois permite otimizar recursos, à medida que direciona a combinação dos recursos organizacionais, conforme aborda o próximo item.

\section{Posicionamento Estratégico}

A importância do posicionamento reside no fato de que ele estimula os consumidores a desenvolverem considerações acerca de uma marca/empresa, além de contribuir para que o público-alvo diferencie as marcas/empresas concorrentes e escolham aquela que percebam como de maior valor (TOLEDO e HEMZO, 1991, p. 12-13).

Para Eckels (1990, p. 128) e para Palmer e Cole (1995, p. 329), a estratégia de posicionamento diz respeito a como o participante vai competir em um determinado segmento, diferenciando-se dos demais para estar em condições de obter sucesso, à medida que pode se constituir em uma vantagem. De maneira mais aplicada, Lovelock e Wright (2001, p. 134) conceituam o posicionamento como “a utilização de ferramentas de marketing por uma empresa para criar uma imagem distinta e desejável na mentalidade dos consumidores-alvo em relação a produtos concorrentes.”

Mühlbacher, Dreher e Gabriel-Ritter (1994, p. 287) afirmam que, geralmente, o posicionamento diz respeito a um processo que busca encontrar e estabelecer uma oferta em um espaço distinto no mercado, às vistas do público-alvo, e que seja a ele mais atrativo do que outras ofertas existentes (MÜHLBACHER, DREHER e GABRIEL-RITTER, 1994, p. 287). Dessa forma, observa-se que a necessidade de diferenciais é intrínseca ao conceito e, mais do que isso, o torna uma diretriz que permite operacionalizar o direcionamento estratégico definido pela empresa.

Toledo e Hemzo (1991, p. 12) concordam com essa visão ao afirmarem que "O posicionamento estratégico tem sido descrito como um instrumento de apoio ao processo de decisões estratégicas relacionadas à conceituação de produtos e empresas, à comunicação de suas características e atributos a segmentos de mercado específicos.”.

De forma subjacente, cabe observar que, ao se posicionar uma oferta, é fundamental a observação de como os clientes atuais e potenciais avaliam as ofertas, e como eles escolhem produtos daquela categoria (TOLEDO e HEMZO, 1991, p. 13). Concordando com essa visão 
acerca da abrangência do conceito, está Kotler (1998, p. 265), ao afirmar que o “posicionamento é o ato de desenvolver a oferta e a imagem da empresa, de maneira que ocupem uma posição competitiva distinta e significativa nas mentes dos consumidoresalvos.”.

Segundo Heskett, Sasser Jr. e Hart (1990, p. 54), em serviços o conceito de posicionamento é expandido para abarcar não apenas o conceito de serviço, mas também as práticas, as políticas e processos, o local e a planta, o fornecedor e o cliente. Palmer e Cole (1995, p. 333) destacam que os serviços podem ser posicionados isoladamente ou como parte da organização, além de afirmarem que os consumidores valorizam mais o posicionamento da empresa do que de serviços individuais. Talvez essa consideração se baseie no fato de que, pela própria natureza dos serviços, que implica algum tipo de contato entre “fabricante” e consumidor, torna-se difícil o posicionamento de ofertas específicas, uma vez que haveria necessidade de estruturas empresariais também específicas.

Portanto, fundamentalmente, entende-se que o posicionamento procura estimular uma percepção no público-alvo da oferta, por meio da adequação das suas variáveis aos aspectos por ele valorizados, de forma que a torne distintiva em relação à concorrência. Disso resulta o seguinte conceito:

"Posicionamento é a definição de uma proposta de valor que interesse à empresa, que seja significativa a um público-alvo e que, na percepção dele, seja distintiva e mais atrativa em relação às propostas elaboradas pela concorrência”.

Assim, de forma simplificada, o posicionamento consiste no desenvolvimento e na transmissão (alicerçada em uma marca) de uma proposta de valor, a partir de aspectos significativos para um determinado público-alvo, os quais serão processados e comparados com concorrentes, originando o posicionamento percebido, conforme apresentado na Figura 1. 


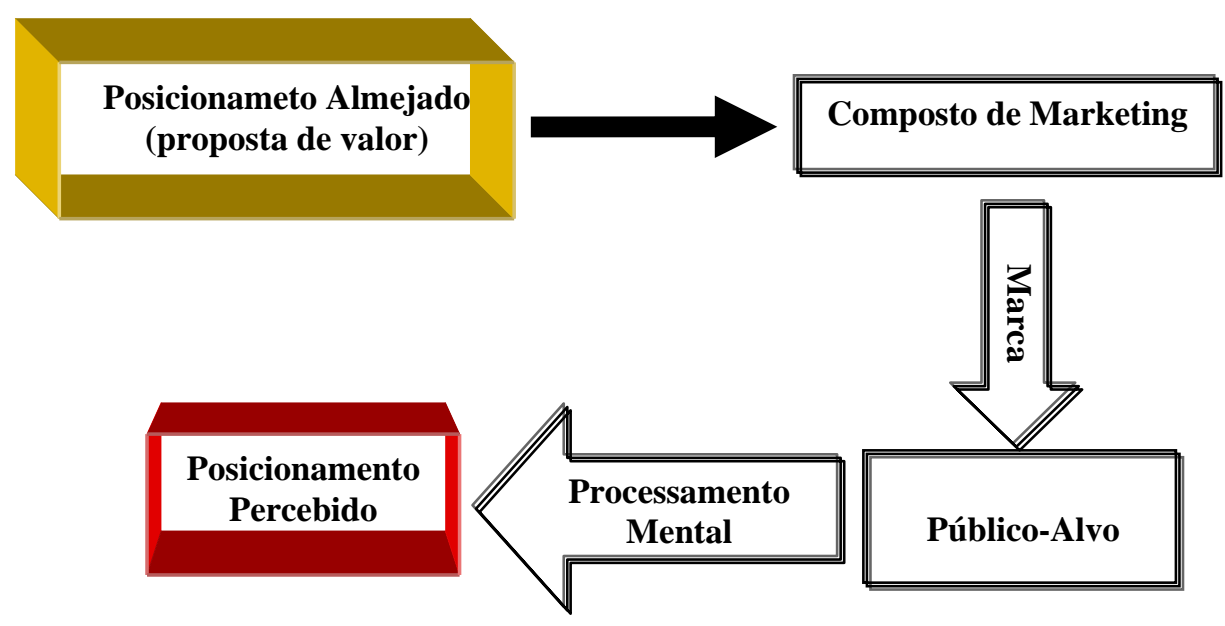

Figura 1 - Esquema simples de posicionamento FONTE: Representação figurativa elaborada pelo primeiro autor.

Segundo Mckenna (1999, p.13-40), o posicionamento é sempre competitivo, pois os consumidores pensam em produtos e empresas em relação a outros produtos e outras empresas, estabelecendo uma hierarquia e, utilizam-se desta para tomar decisões de compra. Assim, uma empresa precisa diferenciar seus produtos em relação a outros existentes no mercado de atuação se quiser que este conquiste uma posição sólida. Para tanto, acredita que os fatores intangíveis dos produtos devem ser enfatizados, pois os tangíveis podem ser facilmente copiados por outras empresas.

De acordo com Aaker e Shansby (1982, p.56-59), para se realizar um posicionamento diversas decisões devem ser tomadas, como a de que segmento de mercado e público-alvo atingir, qual a imagem que se pretende transmitir, e quais as características do produto que serão enfatizadas, entre outras. O posicionamento é uma decisão estratégica porque trabalha com a percepção do consumidor, influenciando o processo de decisão de compra. Este deve ser, portanto, o foco para o desenvolvimento de um programa de marketing.

\subsection{Estratégias e Processos de Posicionamento}

De acordo com Payne (1993, p. 96; 102), o posicionamento depende da capacidade da empresa de se diferenciar dos competidores na entrega de valor aos seus clientes, o que deve se dar pela geração de características que atendam aos seguintes critérios:

- Importância para o consumidor;

- Distintividade; 
- Comunicabilidade;

- Superioridade;

- Acessibilidade por parte do consumidor;

- Proporcionar lucratividade.

O mesmo autor ressalta, ainda, que a seleção do atributo diferenciador apresenta maior chance de sucesso quando condiz com o que o público-alvo já pensa, o que, por sua vez, pode-se constituir em um empecilho para o sucesso do reposicionamento (PAYNE, 1993, p. 102). Portanto, o posicionamento contribui para os objetivos de marketing e organizacionais apenas se ele for capaz de proporcionar valor ao público-alvo da oferta.

A decisão sobre as variáveis que devem ser trabalhadas para que se obtenha o posicionamento pretendido depende da estrutura de mercado em que a empresa atua, do nível de exigência dos seus consumidores, da regulamentação do setor de atividade, e das capacidades da empresa. Além disso, o posicionamento deve ser operacionalizado por atributos intrínsecos e/ou extrínsecos, objetivos e/ou subjetivos, que sejam valorizados pelo público-alvo de uma oferta quando da decisão de compra, conforme apresenta a Figura 2.

Mckenna (1999, p. 13-40) ressalta que os fatores intangíveis dos produtos devem ser enfatizados, pois os tangíveis podem ser facilmente copiados por outras empresas, e Shostack (1987, p. 34), o sucesso do posicionamento é alcançado quando uma empresa consegue estabelecer e sustentar uma posição distintiva para si e para as suas ofertas.

Observe-se que, a despeito do que muitos autores afirmam acerca do posicionamento, a comunicação por si só não é suficiente para contemplá-lo pela abordagem de marketing. No entanto, ela tem seu lugar garantido entre as ações que devem ser realizadas para que o processo seja contemplado no todo. Além disso, o processo é invertido à medida que sua eficácia é majorada a partir de definições estratégicas do processo de posicionamento, por se tratar de uma atividade tática/operacional do ponto de vista da gestão de negócios (TOLEDO e HEMZO, 1991, p. 12). 


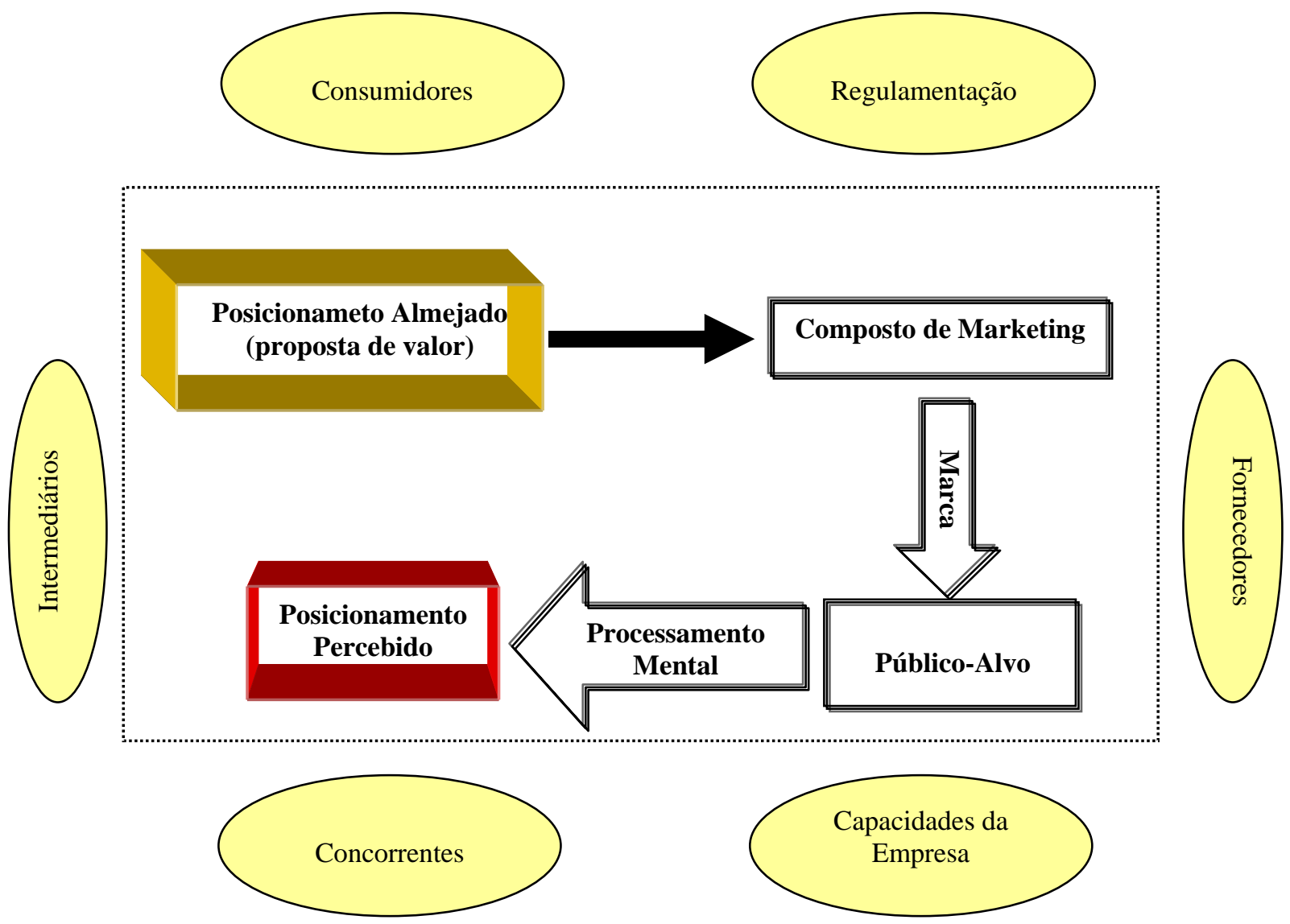

Figura 2 - Condicionantes do posicionamento

FONTE: Representação figurativa elaborada pelo primeiro autor.

Um processo de posicionamento deve levar em consideração algumas questões, tais como: o posicionamento percebido dos produtos concorrentes de outras empresas; as linhas de produtos trabalhadas com vistas a criar e sustentar posicionamentos claros e distintivos a cada uma, evitando a canibalização não planejada; as bases alternativas para o posicionamento (ocasião de uso, dissociação de classe de produtos, entre outras); a seleção da base para posicionar, que depende das características da empresa, do produto, do mercado e do ambiente (WIND, 1982, p. 79-81).

Aaker e Shansby (1982, p. 56) afirmam que, para se realizar um posicionamento, diversas decisões devem ser tomadas, como a de que segmento de mercado e público-alvo atingir, qual imagem se pretende transmitir, e quais as características do produto serão enfatizadas, entre outras. Esse deve ser, portanto, o foco para o desenvolvimento de um programa de marketing.

Cabe reiterar, ainda, que, embora haja forte relacionamento entre a diferenciação e o posicionamento, conforme já explicitado, esse não se reduz à busca do primeiro, pois, trata-se de um conceito mais complexo, que indica a utilização de um conjunto de atividades com 
vistas a induzir um público-alvo a perceber uma oferta em termos relativos a outras, bem como a enaltecer o seu maior valor, às vistas desse público-alvo, em comparação com os valores proporcionados pelos seus concorrentes. De qualquer forma, o posicionamento implica diferenciação, seja objetiva ou subjetiva, real ou percebida, como meio para ofertar valor ao público-alvo a partir de uma combinação dos elementos do composto de marketing. A Figura 3 apresenta essa relação.

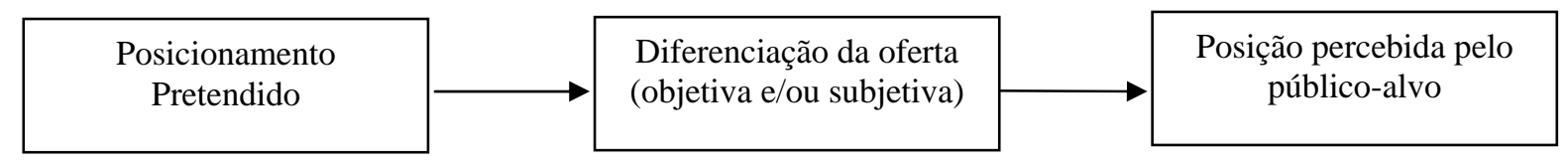

Figura 3 - Operacionalização do posicionamento

Segundo os mesmos autores, há seis estratégias para se posicionar um produto (AAKER e SHANSBY, 1982, p. 57-58):

- Por atributo: ocorre quando se posiciona um produto com base em uma ou mais características ou benefícios oferecidos;

- Por preço e qualidade: associa-se o produto a um determinado nível de preço, qualidade ou valor, como, por exemplo, alta qualidade e preço alto;

- Por uso ou aplicação: associa-se o produto como sendo o melhor ou mais adequado para uma determinada finalidade;

- Por usuário ou classe de usuários: associa-se o produto a um grupo específico de usuários, como, por exemplo, para atletas;

- Pela classe de produtos: associa-se o produto a uma determinada categoria, o que é comum em casos complexos para se apresentar o produto;

- Pela concorrência: realizam-se comparações entre o produto da empresa e os produtos similares dos concorrentes.

A estratégia adotada deve ser condizente com os conceitos e procedimentos que a organização tem desenvolvido, ou seja, a posição transmitida aos seus clientes deve ser consistente com o seu direcionamento estratégico. Assim sendo, o posicionamento deve refletir a identidade da empresa, caso contrário, pode ser uma fragilidade a ser explorada por concorrentes. 
Palmer e Cole (1995, p. 331-332) destacam que o posicionamento envolve a realização de atividades em três etapas:

1. Identificação das forças da empresa e das oportunidades de mercado que podem ser exploradas;

2. Avaliação das possibilidades de posicionamento e seleção da mais apropriada;

3. Desenvolvimento do composto de marketing ao público-alvo com consistência com a posição pretendida.

Pode-se observar que esse processo enfatiza a dimensão interna da empresa, dando pouca atenção à externa, especialmente à concorrência, que, conforme já discutido, é elemento fundamental do processo de posicionamento.

Para Aaker e Shansby (1982, p. 59-62), o processo de desenvolvimento de um posicionamento envolve seis etapas:

1. Identificação dos concorrentes;

2. Verificação de como os concorrentes são percebidos e avaliados pelos consumidores;

3. Averiguação da posição dos concorrentes;

4. Análise dos consumidores;

5. Seleção da posição desejada;

6. Monitoramento da posição.

Note-se que a preocupação principal no modelo operacional exposto acima é relativa aos concorrentes, mais especificamente em como eles são considerados pelos consumidores, não enfatizando a dimensão interna da organização, como as suas capacidades, o que se coloca como risco.

Para Payne (1993, p. 108) o processo de posicionamento consiste em:

- Determinar os níveis de posicionamento (empresa, linha de produto ou individual);

- Identificar os atributos-chave importantes a cada segmento;

- Alocar as marcas da empresa e da concorrência em um mapa de posicionamento, construído a partir de atributos valorizados pelos públicos-alvo; 
- Avaliar as opções de posicionamento (identificar uma nova posição, forçar uma posição já ocupada por concorrentes ou reposicionar os concorrentes);

- Definir os meios de realçar e sustentar a posição almejada.

Observe-se que o processo proposto por Payne (1993) é bastante similar ao proposto por Aaker e Shansby (1982), até mesmo pelo fato de embutirem a aplicação de uma técnica que permite "enxergar" os posicionamentos de diversos competidores: o chamado "mapa perceptual”, concebido a partir de técnicas estatísticas sofisticadas, em especial do MDS Multidimensional Scaling. Segundo Boone e Kurtz (1998, p. 242) e Cravens (1987, p. 378), o MDS gera um gráfico que permite visualizar como os consumidores percebem determinados produtos em relação às variáveis consideradas, as quais devem ser relevantes para eles. A partir daí, deve-se definir um adequado plano de marketing que possibilite o posicionamento do produto, conforme intencionado pela empresa (URBAN, HAUSER e DHOLAKIA, 1987, p. 104).

De acordo com Jain (2000, p. 364), os mapas perceptuais, por permitirem visualizar a posição de uma marca em relação às suas concorrentes, contribuem para que os estrategistas possam:

- Entender como produtos e serviços são percebidos por diferentes grupos de consumidores em termos das suas forças e fraquezas;

- Entender as semelhanças e dessemelhanças entre produtos e serviços;

- Encontrar espaço para reposicionar produtos e serviços;

- Posicionar novos produtos e serviços no mercado;

- Monitorar o impacto das ações de marketing no posicionamento de produtos e serviços.

Mühlbacher, Dreher e Gabriel-Ritter (1994, p. 289-290) criticam o processo apresentado por Aaker e Shansby (1982) em razão dele desconsiderar a análise interna, o que julgam fundamental, já que o posicionamento tem na diferenciação um dos seus pilares. Assim, para eles, o desenvolvimento de diferenças que se constituem em vantagem competitiva deve levar em consideração as capacidades da empresa, dos seus concorrentes e as necessidades e os desejos do público-alvo.

Dessa forma, o processo de posicionamento proposto por esses autores tem início com a definição e a análise dos consumidores atuais e potenciais de um determinado campo de negócio para, posteriormente, se realizar o processo de segmentação. Em paralelo com a 
definição dos segmentos, deve-se realizar uma superficial identificação e análise dos concorrentes atuais e potenciais em termos de poder e de estratégias gerais.

Após essa etapa inicial, devem-se realizar análises, apenas, nos segmentos mais atrativos, o que inclui a definição dos fatores-chave de sucesso e as suas importâncias em cada segmento escolhido, bem como uma análise detalhada da empresa e dos seus principais concorrentes. A partir daí, são obtidas as capacidades diferenciais, que devem ser consideradas para a definição dos segmentos de interesse, e a definição dos benefícios que serão apresentados a cada segmento, que por sua vez deve servir de base para a definição do posicionamento pretendido, o qual deve ser sustentado pelas decisões do composto de marketing. (MÜHLBACHER, DREHER e GABRIEL-RITTER, 1994, p. 291-292).

Essa abordagem tem seu valor reconhecido, especialmente, por considerar tanto a dimensão externa quanto a interna da organização, e por reunir os processos de segmentação e de posicionamento em um único modelo, buscando amenizar a possível existência de dificuldades de convergência entre essas atividades.

Uma pequena crítica que pode ser feita ao modelo acima exposto é o fato de que, em virtude de as atividades e preocupações serem dispostas de forma seqüencial, o tempo necessário para a realização do processo tende a ser grande, o que cria uma fraqueza a ser explorada por concorrentes - o que talvez seja por questões puramente didáticas. Uma forma de amenizar essa “deficiência” é a realização conjunta das análises relativas ao mercado, à concorrência e à empresa.

A fim de contribuir tanto para o conhecimento relativo ao posicionamento estratégico de empresas do setor de turismo, quanto para a prática gerencial do processo, a seguir apresentase os resultados da pesquisa realizada, precedida pela sua metodologia.

\section{Metodologia da Pesquisa de Campo}

Em vista da importância do posicionamento estratégico na contribuição para a competitividade empresarial, a pesquisa realizada teve por objetivo principal verificar a consonância entre a prática e a teoria apresentada ao seu respeito, bem como averiguar a existência de aspectos não abordados pelos modelos apresentados, uma vez que eles não foram verificados na prática, nem tampouco originados a partir de pesquisa empírica. Para tanto, foram definidos os seguintes objetivos específicos, que originaram as variáveis operacionais: 
- Verificar o grau de importância do posicionamento estratégico para a empresa pesquisada;

- Verificar as práticas realizadas pela empresa pesquisada acerca do posicionamento;

- Verificar as dificuldades e os resultados do processo.

Os objetivos propostos e a finalidade do presente estudo indicaram como mais apropriada a pesquisa do tipo descritiva, a qual foi realizada por meio do estudo de caso (VERGARA, 1998, p. 45; YIN, 2001, p. 33). Ressalte-se que, muito embora o estudo de caso seja comumente apresentado como um método de pesquisa específico para estudos exploratórios, Yin (2001, p. 23) esclarece que estudos descritivos e causais também podem ser realizados por meio desta técnica. Isso é possível porque a forma de coleta de dados deve se adaptar aos objetivos e às especificidades de cada estudo. Yin (2001, p. 23) acrescenta, ainda, que quando utilizado o método do estudo de caso, o objetivo do pesquisador é realizar generalização analítica, e não estatística.

Para a contribuição empírica foi selecionada a empresa Sabre, em vista de se tratar de uma grande empresa e do dinamismo da competição no seu setor de atuação. A coleta de dados se deu por meio de uma entrevista pessoal com uma executiva de contas da referida empresa.

O estudo de caso deu-se por meio da aplicação de um roteiro semi-estruturado em entrevista pessoal, a qual foi gravada, com a concessão da entrevistada, com o objetivo de reduzir o tempo da entrevista e de melhor aproveitar as informações fornecidas. A entrevista foi realizada pelos dois primeiros autores do presente trabalho. A primeira parte do roteiro buscou melhor conhecer a empresa e a entrevistada, enquanto que a segunda abordou o tema da pesquisa propriamente dito.

A análise foi do tipo interpretativa e buscou correspondência com a teoria apresentada, de forma que se pudesse reforçar ou questionar informações obtidas por meio da revisão da literatura sobre o assunto em questão, haja vista a não concepção de hipóteses teóricas que buscassem antever respostas ao problema de pesquisa exposto (YIN, 2001, p. 134). Não foram analisados documentos da empresa pesquisada, mas foi solicitado à entrevistada que considerasse fatos reais para a construção das respostas, buscando minimizar uma das fraquezas da utilização da entrevista pessoal como fonte do método estudo de caso: a tendenciosidade (YIN, 2001, p. 114). 


\section{Apresentação dos Resultados do Estudo de Caso}

\subsection{Carcaterização da empresa}

A Sabre Travel Network é uma empresa norte-americana, fornecedora líder em tecnologia e distribuição para a indústria de viagens. Com mais de 50\% de participação de mercado no Brasil, o Sabre está presente em mais de 53.000 agências de viagens em 45 países. A empresa também possui a liderança de número de reservas ao redor do mundo, com 36\% do mercado. Através de um único sistema de reservas o cliente Sabre tem acesso a mais de 400 companhias aéreas, aproximadamente 70.000 hotéis, 37 locadoras de veículos, 9 companhias marítimas e 220 operadoras de viagens.

No mercado de atuação da Sabre existem três concorrentes principais: o Amadeus, que é líder na Europa e pertence a uma parceria entre as companhias Air France, Ibéria e Luftanza, o Galileu, que é americano e está vinculado a United Air Lines e um último que pertence à Delta Air Lines. A Sabre é americana e pertence à American Air Lines, e tem a liderança de mercado na América e na Ásia.

A estratégia do Sabre sempre foi se posicionar como líder em tecnologia e excelência em serviços. Como conseqüência disso a empresa se comprometia em desenvolver soluções completas de grande valor agregado para os clientes. Por exemplo, o Sabre foi o primeiro GDS (global distribution system) a oferecer acesso e venda das tarifas negociadas nos hotéis do Brasil. A empresa foi também pioneira na utilização de ferramentas como relatórios de reservas on-line, serviço de chat com os departamentos de help desk, executivos de contas e treinamento, inscrições on-line em cursos, ferramentas de treinamento à distância e o conceito de atendimento através de uma Central de Relacionamento com o Cliente.

No entanto, nos últimos dois anos, devido a mudanças no ambiente em que a empresa atua e à saída de um importante player do mercado, a nova palavra de ordem dentro da empresa passou a ser "redução de custos", sendo este, portanto, seu atual direcionamento estratégico.

\subsection{Variáveis Operacionais}

\subsubsection{Importância do posicionamento}

De acordo com a entrevistada, uma empresa deve empreender um processo de posicionamento em vista da importância de manter a empresa competitiva no mercado, principalmente através do monitoramento do ambiente externo. 
No caso do praticado pela Sabre, o grande propósito foi a redução de custos. Segundo a entrevistada, “O Sabre é uma empresa muito focada no desenvolvimento de produtos e no desenvolvimento de tecnologia, que procura sempre estar na liderança e ser a primeira. Os custos nunca foram uma preocupação para a empresa.”. Porém, o aumento da sensibilidade em relação ao preço por parte dos clientes de todo o mundo e o encolhimento do mercado brasileiro, que motivou inclusive a saída de um grande player, indicam a necessidade de alterar o modelo de negócio da empresa e os produtos que são oferecidos ao mercado. Com isso, perde-se um importante aspecto positivo, que é o conceito de "solução completa" vinculado à empresa. Mas, por outro lado, o produto ficou mais flexível e o seu custo diminuiu consideravelmente, estando mais de acordo com as expectativas dos seus clientes.

O relacionamento da Sabre Travel Network com um cliente, por exemplo, uma agencia de viagem, ocorria da seguinte maneira: o Sabre disponibilizava, primeiro, toda a infra-estrutura, incluindo computadores, linha de dados e servidor, para depois dar acesso às informações existentes no sistema e fazer a manutenção. Desta maneira a Sabre acreditava que garantia uma compatibilidade entre o conteúdo e a forma de acesso.

Por um lado, houve a percepção de que os clientes estavam recebendo benefícios que não representavam valor. Isto porque os concorrentes, que não têm produtos tão elaborados, serviços de alta qualidade, nem uma equipe tão bem treinada, estão colocando pacotes no mercado com benefícios muito menores e também com preços muito menores e o Sabre não tem condições, dentro do modelo de negócios atual, de praticar tais preços. Através desta percepção, a empresa sente que sua posição no mercado pode ser ameaçada.

Os custos predominantes do Sabre não são diretos. No relacionamento com um cliente, existiam três ou quatro outras empresas envolvidas, prestando serviços para o cliente, como terceiros, que obviamente cobram por estes serviços. A Sabre, por sua vez, disponibiliza o conteúdo informacional, porém, os custos derivados do serviço ampliado são repassados para o cliente. Desta forma, os clientes pagavam por um serviço que não é da Sabre, que trabalha eminentemente com informação. No entanto, o produto do Sabre tem que arcar com os custos relativos a serviços prestados por outras empresas que são agregados no produto e elevam de maneira substancial o preço da oferta.

Por outro lado, de acordo com a entrevistada, "Quem paga realmente pelo nosso serviço são as companhias aérea [...] A companhia aérea paga um espaço no meu sistema. A agência compra este espaço, a companhia aérea me paga. A agencia, o meu cliente, ganha tudo de graça. Mas se compromete a realizar um certo número de negócios ou vendas.” 
As companhias aéreas, em um movimento que se estende há décadas, procuram enxugar seus custos. Desta maneira, elas passaram a tirar as comissões das agencias de viagens e eliminar o custo de ter um sistema de informação. Até algum tempo atrás, quando não havia um sistema on line bem desenvolvido e acesso rápido à Internet, as companhias aéreas não tinham eficácia na distribuição, e utilizavam-se as agências e operadoras de viagens como canal até o consumidor. Atualmente, com plataformas compatíveis, linhas de Internet e tecnologia bem desenvolvida, uma tendência é a eliminação dos canais e a distribuição sem intermediários pelas companhias aéreas.

A estratégia do Sabre de enxugar custos e focar no seu produto, isto é, a tecnologia da informação, é compatível com o momento em que as companhias aéreas não irão mais precisar de intermediários para ofertar seus produtos e os serviços Sabre serão eliminados devido ao corte de custos.

\subsubsection{Operacionalização do posicionamento}

De acordo com a entrevistada, a Sabre teve uma preocupação muito grande em preparar a equipe para o processo de posicionamento. Todos os funcionários receberam um treinamento de Marketing com o objetivo de esclarecer questões relevantes para qualquer negócio, como, análise ambiental, estratégia de marketing, posicionamento, aspectos comunicacionais, índices de market share, análise da concorrência, etc. Depois, a empresa empreendeu um treinamento de Finanças, também para todos os funcionários, em que foram abordados temas como administração financeira, conceitos básicos de receita, custos, demonstrativos, etc.

O propósito dos treinamentos foi exatamente o de evidenciar para toda a equipe a situação em que o Sabre estava inserido no mercado brasileiro. Os próprios funcionários foram percebendo que o mercado estava diminuindo e que isto diminuiria a receita do Sabre. Desta forma, houve uma conscientização geral de que a mudança seria necessária.

A decisão estratégica de orientar a empresa para uma liderança em custo partiu da matriz. No entanto, a implementação desta, através de planos e atividades operacionais foram determinados pelas filiais, visando uma maior adaptação das realidades locais. Portanto, quando, no Brasil, chegou a nova orientação da empresa, a equipe Sabre já estava preparada e comprometida.

A grande alteração resultante do processo de redução de custos foi o corte de todos os serviços adicionais ao produto principal do Sabre. Nos novos contratos de prestação de serviço, o que é acordado é o oferecimento do acesso ao sistema Sabre de informações, que é 
produto propriamente dito. É de responsabilidade da agência de viagem arcar com os custos de instalação de equipamentos, conexão de Internet, provedores, etc. Esta medida trouxe uma redução significativa no preço do produto.

Não houve alteração no pessoal, na infra-estrutura da empresa e nem na entrega do serviço ao cliente. Em relação à comunicação, que tem um caráter mais institucional, o Sabre, que sempre esteve nas principais feiras, pretende manter este modelo. Para o próximo ano, devido ao bombardeio de comunicação que tem sido feita pela concorrência, o Sabre vai patrocinar eventos do turismo.

A formação de parcerias, como a feita com a Telefônica, para prover linha de dados, foi disponibilizada para os clientes que realmente acreditavam que este serviço era essencial, porém, a um custo muito menor do que era praticado anteriormente.

O determinante neste processo, segundo a entrevistada, foi o relacionamento com o cliente. "Existe uma relação de confiança entre os clientes e o Sabre. Isto devido à marca, ao histórico da empresa. Os clientes acabam confiando que se o Sabre está se posicionando desta maneira é porque é uma boa atitude”.

O relacionamento com o cliente no Sabre é baseado em segmentos de clientes. A atividade do cliente é considerada, porém, o aspecto determinante para a segmentação é o volume de vendas. A empresa identifica quatro segmentos. O primeiro é o grupo denominado Elite, que tem um volume de negócios muito grande e não sofreu nenhuma alteração no relacionamento com a Sabre (gerentes exclusivos). No segundo segmento também não houve alteração. As alterações em questão se manifestam na freqüência do número de visitas ao cliente. Para os dois segmentos menores em volume de vendas as visitas de gerentes, que ocorriam a cada dois meses, foram eliminadas, foi criado um centro de gerência com base em SP para atender estes clientes virtualmente.

\subsubsection{Dificuldades e resultados do processo}

O intervalo, entre o período em que o processo de redução de custos e eliminação de serviços adicionais foi implementado, a vigência dos contratos existentes e a adição de novos contratos, podem ser considerados fatores críticos. Os grandes clientes atuais ou novos sabem como a Sabre operava. Mas eles também sabem do elevado custo relacionado a "solução completa”. As agencias de viagens, por exemplo, para contar com toda a infra-estrutura era oferecida deveriam mobilizar um volume de vendas muito grande. 
A solução encontrada pela Sabre foi, através do relacionamento com os clientes, mostrar que o sistema de informações é o mesmo e que o atendimento também é o mesmo, porém, mediante um custo muito menor. O custo eliminado foi o dos serviços adicionais, como fornecimento de equipamentos e conexões. Um ponto surpreendente neste momento é que muitos clientes perceberam como positivas as alterações. Eles relatam que as alterações tornaram o produto do Sabre mais flexível e adaptado as necessidades individuais.

Em relação à concorrência, neste processo, o Sabre pode estar correndo certo risco, uma vez que o principal concorrente, o Amadeus, traz ao mercado uma oferta de "solução completa", ou seja, em um mercado restrito, os dois principais players estão adotando estratégias de negócios completamente opostas.

Um cliente potencial muito típico é aquele estudante de turismo que se forma e decide abrir uma agência de viagens. Para se interagir neste mercado, ele procura o sistema do Sabre ou do concorrente. Este cliente geralmente não tem informações específicas a respeito do sistema Sabre e acaba sendo conquistado pelo concorrente, que oferece a "solução completa”.

A principal dificuldade que o Sabre enfrentou neste processo foi em relação a parte legal da prestação de serviços. Para implantar alguma alteração nos contratos com os clientes antigos é praticamente necessário renovar o contrato. Segundo a entrevistada: “A inflexibilidade dos contratos foi muito negativa neste processo”.

Outro ponto negativo foi a modificação no equipamento para acessar o sistema. Quando o Sabre era responsável pelo sistema havia uma garantia de funcionamento, porém, como não há mais garantias, dependendo do equipamento, pode haver lentidão no acesso aos dados.

Em relação às pessoas, de acordo com a entrevistada, como foi tudo muito bem comunicado, não houve problemas, nem aversão ao processo. E, apesar de todas as implementações visando à diminuição dos custos, a Sabre aumentou o seu número de funcionários, o que é positivo, uma vez que demonstra ao mercado uma empresa sólida e de confiança, porque, querendo ou não, notícias de reduções no quadro de pessoal tendem a afetar negativamente a imagem da empresa. Com a redução de custos e alteração de produto, a receita apresentou crescimento de $4 \%$ a $5 \%$ nos últimos dois anos, alcançando, no ano passado, mais de 50\% em market share. Houve, também, crescimento no lucro.

De maneira geral, as companhias aéreas estão sinalizando que o modelo atual está com os dias contados. O que a Sabre está fazendo é, através da divisão de Travel Network, investir em 
pesquisas, garantir um tempo de vida maior, enquanto outras empresas da holding possam se desenvolver ou criar um novo conceito de venda de viagens.

\section{Conclusões}

Em um movimento julgado necessário pela empresa estudada, em vista de alterações no seu ambiente competitivo e para se adequar aos interesses dos seus clientes, a Sabre definiu orientar-se para o mercado com base em liderança em custos, focando o seu serviço, tecnologia de informação, delegando aos próprios clientes a tarefa de organizar a estrutura necessária para usufruir do serviço ofertado.

No geral, observou-se que as atividades contempladas pela Sabre para a realização do seu posicionamento estratégico foram condizentes com os modelos observados na literatura específica, em especial ao mais abrangente, que é o de Mühlbacher, Dreher e Gabriel-Ritter (1994). No entanto, no que tange à análise da dimensão interna, com vistas à observação de potencialidades a serem exploradas pelo posicionamento, conforme sugerido pelos modelos apresentados pela literatura de marketing, a empresa trouxe à tona a necessidade de se treinar as pessoas envolvidas, como forma de obter o comprometimento daqueles que efetivamente implementarão o posicionamento definido, o que denota a importância da cultura organizacional para o sucesso do posicionamento estratégico.

Manter a organização competitiva significa mantê-la ajustada ao seu ambiente, especialmente às necessidades e desejos do seu público-alvo. Assim sendo, em vista da necessidade de ajustes no posicionamento, seja para torná-lo consistente com o desejado, seja para adequá-lo às oportunidades existentes, o reposicionamento emerge como uma atividade fundamental, visto que é imperativa a necessidade de organizações competitivas serem orientadas para o mercado, colocando-se como um assunto a ser explorado em futuros estudos. Em última análise, essa orientação denota o enraizamento de premissas e atividades de marketing em toda a organização e, em especial, na alta direção, por ser ela a responsável pelos resultados perante os seus diversos públicos.

Disso decorre que o posicionamento deve ser avaliado regularmente a fim de se identificar mudanças nas preferências do público-alvo e nas estratégias dos concorrentes, para que possam ser tomadas medidas corretivas. 


\section{Referências Bibliográficas}

AAKER, David A. e SHANSBY J. Gary. 1982. Positioning your product. Business Horizons. Greenwich, v. 25, n. 3, p. 56-62.

BOONE, Louis E. e KURTZ, David L. 1998. Marketing contemporâneo. Rio de Janeiro: LTC.

CRAVENS, David W. 1987. Strategic marketing. Illinois: Richard D. Irwin, Inc.

DAY, George S. 1999. The market driven organization: understanding, attracting and keeping valuable customers. New York: The Free Press.

ECKELS, Robert W. 1990. Business marketing management: marketing of business, products and services. New Jersey: Prentice-Hall, Inc.

HESKETT, James L.; SASSER JR., W. E.; HART, Christopher W. L. 1990. Service breakthroughs: changing the rules of the game. New York: Free Press.

JAIN, Subhash C. 2000. Marketing: planning \& strategy. Cincinnati: South-Western College Publishing.

LOVELOCK, Christopher e WRIGHT, Lauren. 2001. Serviços: marketing e gestão. São Paulo: Saraiva.

KOTLER, Philip. 1998. Administração de marketing: análise, planejamento, implementação e controle. São Paulo: Atlas.

MACHADO, Jorge A. S. 1999. Um modelo para serviços ao cliente e sua adequação na indústria automobilística. Tese de Doutorado. São Paulo: Programa de Pós-graduação em Administração, Faculdade de Economia e Administração da Universidade de São Paulo.

MCKENNA, Regis. 1999. Estratégias de marketing em tempos de crise. São Paulo: Publifolha.

MÜHLBACHER, Hans; DREHER, Angelika; GABRIEL-RITTER, Angelika. 1994. MIPS Managing industrial positioning strategies. Industrial Marketing Management. New York, v. 23, n. 4, p. 287-297.

PALMER, Adrian; COLE, Catherine. 1995. Services marketing: principles and practices. New Jersey: Prentice-Hall.

PAYNE, Adrian. 1993. The essence of services marketing. London: Prentice-Hall.

PORTER, Michael E. 1986. Estratégia competitiva: técnicas para análise de indústrias e da concorrência. Rio de Janeiro: Campus.

SHOSTACK, G. Lynn. 1987. Service positioning through structural change. Journal of Marketing. Chicago, v. 51, n. 1, p. 34-43.

TOLEDO, G. L. e HEMZO, M. A. 1991. O processo de posicionamento e o marketing estratégico. In: Encontro Anual da Associação Nacional de Programas de Pós-Grauação em Administração ENANPAD, XV, Belo Horizonte, Anais. Belo Horizonte: ANPAD.

URBAN, Glen L.; HAUSER, John R.; DHOLAKIA, Nikhilesh. 1987. Essentials of new product management. New Jersey: Prentice-Hall, Inc.

VERGARA, Sylvia C. 1998. Projetos e relatórios de pesquisa em administração. São Paulo: Atlas, WIND, Yoram. 1982. Product policy: concepts, methods, and strategy. Menlo Park: Addison Wesley Publishing Company.

YIN, Robert K. 2001. Estudo de caso: planejamento e métodos. Porto Alegre: Bookman,

\section{Recebido em: 6/10/2005 (1a versão) 10/06/2006 (2a versão) Aprovado em: 18/08/2006}

